\title{
patología de las obras de fábrica
}

A. GARCIA MESEGUER, Dr. ingeniero de caminos

$689-4$

"Todo el cuerpo humano es así; como construcción no está mal, pero como material, un fracaso."

MAX FRISCH ( «Homo Faber»).

\section{simopsis}

Este artículo recoge y amplía la conferencia pronunciada por su autor, bajo el mismo título, en el Ministerio de Obras Públicas, el 12 de febrero de 1970.

Tras una breve referencia a las obras metálicas y de madera, se analiza con detalle la patología del hormigón como material estructural, estudiando las diversas fisuras que pueden presentarse y su significado. Se sistematizan y clasifican después las causas más frecuentes de anomalías en las estructuras de hormigón, presentando ejemplos ilustrativos $y$ terminando con una breve exposición de las ayudas que pueden encontrar en los laboratorios especializados los técnicos que han de enfrentarse con problemas de patología en sus obras.

\section{introducción}

He utilizado en el título de esta charla una palabra tomada de la medicina, cuyo significado es «tratado de las enfermedades». Hablar de enfermedades de las obras de fábrica equivale a asimilarlas a seres vivos y, efectivamente, esta asimilación no puede ser más justa. Porque las obras, como las personas, son engendradas, con alegría o con dolor, en un momento culminante de inspiración del proyectista. Luego se gestan, se desarrollan y se construyen: nacen, vienen al mundo. Y a partir de ese momento, quedan expuestas a los avatares del ambiente y participan de su ecología. Porque también puede aplicarse a las estructuras esta expresión, tomada esta vez de la biología, para indicar el conjunto de influencias que ejerce el medio sobre los seres.

Cometemos a veces la ligereza de pensar que una vez acabada una obra se han terminado los problemas que toda construcción plantea. Y bueno es recordar aquí que eso no es así, sino que empieza una etapa - la vida de la obra - en la que ésta requerirá vigilancia y cuidados. Porque, como los seres vivos, las obras sufren los rigores de la temperatura, se dilatan en verano y se encogen en invierno. Reciben las inclemencias del tiempo, se empapan de agua, se hinchan, se deforman o se resecan, se contraen y endurecen. $Y$ con el paso del tiempo los materiales, como las personas, envejecen, en un proceso continuo de evolución de sus características. Todo ello sin contar los efectos que en las obras producen las cargas que deben soportar, cuya actuación más o menos permanente imprime su huella en las mismas. 
Las anteriores circunstancias y muchas más justifican el que pueda hablarse de una patología de las estructuras. Y frente a tantas enfermedades, las obras se comportan de diversas maneras, mostrando una sintomatología más o menos variada (cambios de coloración, fisuraciones, descascarillamientos, etc.), cuyo conocimiento es imprescindible para, con buen tino, dictaminar causas y aplicar remedios.

En este planteamiento se sitúa el marco de mi charla.

\section{metal y madera}

El primer condicionante del comportamiento de una estructura, a lo largo de su vida, es el material de que está constituida. Sería vano pretender tratar en una charla todos los materiales, por lo que me referiré muy de pasada al metal y la madera, para detenerme luego en el más complejo e interesante desde el punto de vista patológico: el hormigón.

Las estructuras metálicas utilizan un material único, muy homogéneo y confiable: el acero. Por ello, sus enfermedades no suelen ser difíciles de diagnosticar y, para lo que aquí interesa, podrían agruparse en tres apartados. En primer lugar, la CORROSION en todos sus grados, desde el más leve de oxidación más o menos ligera o estabilizada, hasta el más grave y aparatoso de fuertes expansiones con desprendimiento del material en lajas y destrucción completa del elemento. En segundo lugar, la FATIGA, fenómeno típico de los materiales metálicos, que ven disminuida su resistencia por aplicación repetida de ciclos - de millones de ciclos- de carga, con la consiguiente variabilidad en el valor de la ténsión máxima, e incluso en el signo de la misma. Y en tercer lugar, los EFECTOS DE IMPACTO, a los que son más susceptibles que las estructuras de hormigón debido al pequeño espesor de las almas de sus elementos, y que pueden ocasionar abolladuras más o menos locales, fenómenos de inestabilidad, etc.

Las medidas de protección de las estructuras metálicas son también relativamente simples de recordar. En primer término, hay que asegurar la limpieza de la obra. En seguida, la pintura, como modo universal de protección del acero contra la corrosión. Otros revestimientos eficaces son las pinturas bituminosas, el cincado y el revestimiento puro y simple a base de morteros, materiales plásticos, asfálticos u otros. Por último, hay que recordar las aleaciones inoxidables y las protecciones catódicas.

En la resolución de problemas que se nos puedan presentar relacionados con materiales metálicos puede colaborar muy eficazmente el CENIM (Centro Nacional de Investigaciones Metalúrgicas), sito en la Ciudad Universitaria de Madrid, que tiene montado un servicio de asistencia técnica para estos menesteres.

En cuanto a la madera, rara vez se emplea como material estructural hoy. Pero también es rara la obra en la que no se utilice, con misión más o menos secundaria, la madera. Desde el punto de vista que analizamos, la palabra MADERA debe sugerirnos inmediatamente la idea de SUSCEPTIBILIDAD A LA HUMEDAD-SEQUEDAD. La madera es, en efecto, muy sensible al grado de humedad y lo acusa inmediatamente con los correspondientes cambios de volumen. Y este hecho $\tan$ simple y conocido es la causa de muchas dificultades, sea que un encofrado se hincha y alabea por no haberse previsto las oportunas juntas, sea que un revestimiento se cuartea por no haberlo independizado de elementos de madera que se estiran y se encogen varias veces al año.

La patología de la madera es también relativamente simple. Hay que pensar en su PUDRICION, debida a la actuación de hongos que se alimentan de madera, la reblandecen, decoloran o afofan. El clima es variable fundamental en este hecho. Hay que pensar en los XILOFAGOS MARINOS, presentes en casi todos los puertos del mundo, cuya velocidad de actuación destructiva suele ser muy grande. Hay que pensar, en fin, en los INSECTOS, sean coleópteros (carcoma), termitas, abejas... Contra todas estas enfermedades nos defendemos a base de tratamientos preventivos que revisten la forma de impregnaciones con productos adecuados; o mediante revestimientos (pintura, metal, hormigón, plásticos, etc.) aplicados con diversas técnicas más o menos especializadas.

En el campo de la madera podemos recurrir, cuando necesitemos ayuda, al Instituto de Investigaciones Forestales, en Puerta de Hierro, que posee un servicio de asistencia técnica al respecto.

No conozco el grado de atención que este Centro dedica a problemas constructivos, pero imagino que no será muy grande, dado el escaso empleo que la madera tiene en nuestro país como material primario. Otros países, como Portugal, dedican grandes esfuerzos al tema, debido sin duda a la mucha madera existente en sus territorios de Africa. Concretamente, el Laboratorio Nacional de Ingeniería de Lisboa tiene todo un departamento consagrado a la investigación de la patología de la madera y sus remedios. 


\section{hormigón}

Y llegamos al material hormigón, material esencialmente heterogéneo, que nos fabricamos en obra con piedras más o menos gordas, un polvo llamado cemento y agua; cada componente tiene una naturaleza distinta entre sí; y distinta para cada caso particular. $Y$ para colmo de heterogeneidad, les ponemos dentro unas barras de acero. Todo eso significa que la patología del hormigón armado es compleja, ya que engloba la de varios materiales; y también significa que los orígenes de enfermedades se amplían en relación con los materiales primarios antes comentados, ya que en este caso la fabricación se hace en obra y las causas de anomalías pueden comenzar en los mismos orígenes de su nacimiento como material.

A cambio de lo anterior, el hormigón presenta casi siempre unos síntomas patológicos bien patentes que nos avisan de que algo está ocurriendo. A veces da tiempo de actuar y a veces no, pero en general y, salvo errores graves de proyecto, el hormigón avisa siempre.

Entre esos síntomas se encuentran los cambios de coloración, los descantillamientos y las degradaciones superficiales más o menos profundas. Pero sobre todo, se encuentra uno que es el rey de todos ellos: la fisuración. La fisuración es como la fiebre en los enfermos, un síntoma de anormalidad. Y aunque a primera vista pudiera parecer que todas las fisuras son más o menos parecidas, un análisis más detallado demuestra que, en general, cada fenómeno lleva consigo un tipo de fisuración específica, cuyo buen conocimiento interesa para poder diagnosticar con acierto.

Las figuras y comentarios siguientes nos ayudarán en el análisis a que me refiero. En dichas figuras he preferido escoger los ejemplos más claros, aunque no pertenezcan estrictamente al campo de las obras de fábrica.

\section{fisuras de afogarado}

Surgen estas fisuras por causa de la desecación superficial del hormigón, cuando el cemento aún no ha terminado de fraguar, es decir, en las primeras horas. Al existir una pérdida de agua por evaporación, el efecto de contracción es muy marcado y aparece la fisura. El fenómeno se produce cuando existe soleamiento directo o, aún más marcadamente, por acción del aire seco sobre superficies de hormigón no protegidas.

Como fácilmente se comprende, a mayor superficie de exposición y a menor espesor del elemento, corresponde mayor probabilidad de ocurrencia del fenómeno.

Si el elemento es de espesor variable, las fisuras se localizan en las zonas más delgadas (fig. 1, caso de un forjado), en las que es mayor la importancia relativa de la contracción por secado prematuro. Si el elemento tiene espesor uniforme, sin direcciones preferentes, las fisuras suelen distribuirse caprichosamente, ofreciendo el aspecto clásico de piel de cocodrilo (fig. 2). Es de hacer notar que en estos casos de fisuración aleatoria, las fisuras vienen a cortarse casi siempre con ángulos aproximadamente rectos. Ello se debe a que, antes de aparecer una fisura, la superficie del hormigón se encuentra sometida a equitracciones. Al surgir la fisura, la tracción que le es normal queda anulada (fig. 3), pero se mantiene la que le es paralela, la cual puede originar una nueva fisura perpendicular a la anterior.

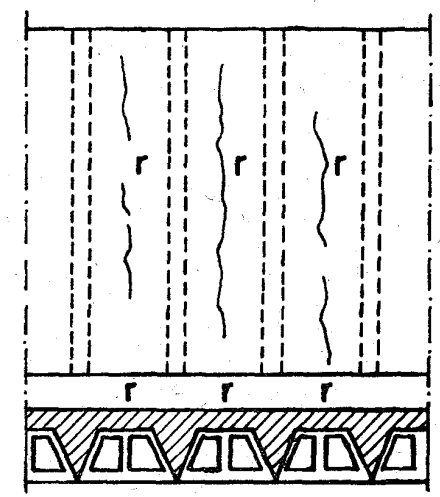

Fig. 1

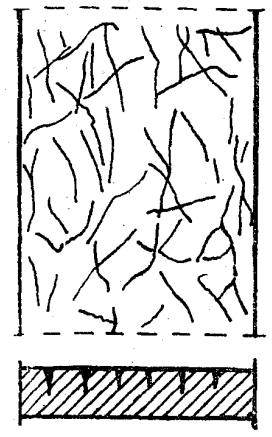

Fig. 2

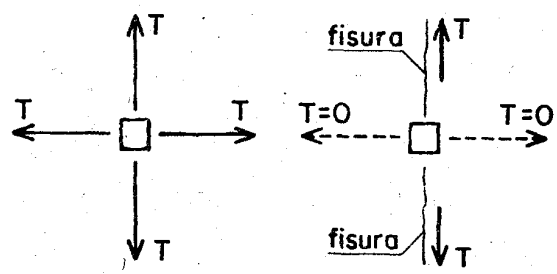

Fig. 3 
Lo dicho permite establecer la siguiente regla práctica: Si dos fisuras se cortan según un ángulo muy agudo, puede asegurarse que al menos una no es de afogarado-retracción.

Con elementos de gran espesor, las fisuras pueden aparecer en varias familias, siguiendo direcciones que han sido preferentes durante el hormigonado. Un ejemplo típico de este caso se presenta en las losas de pavimentos de hormigón, las cuales, si no son protegidas inmediatamente del sol fuerte y, sobre todo, del aire seco, muestran fisuras de afogarado paralelas al eje de la carretera, es decir, en la dirección del hormigonado.

En la figura 4 se representa, además de una de las familias mencionadas, otro fenómeno típico, que es el llamado «nido de fisuras». Aparece en aquellas zonas donde, por cualquier causa, se ha producido una concentración de pasta rica en cemento y sin árido grueso, la cual retrae mucho más que el resto del hormigón.

Las fisuras de afogarado vienen favorecidas, a igualdad de las restantes variables, por el empleo de grandes dosis de cemento; de elevadas relaciones agua/cemento; de cementos molidos demasiado finamente o de muy alta categoría; y de mezclas muy ricas en finos, sea por la arena empleada, sea por contenidos de arcilla presentes como impureza de los áridos.

Como resumen anotamos las siguientes características que, como norma general, poseen las fisuras de afogarado:

- aparecen en las primeras horas (1-2-4-10 horas);

- tienen una profundidad del orden de 10 a $20 \mathrm{~mm}$, rara vez mayor de $50 \mathrm{~mm}$;

- aparecen casi siempre en grupo;

- aparecen en tiempo seco, con sol directo y/o con viento, incluso débil.

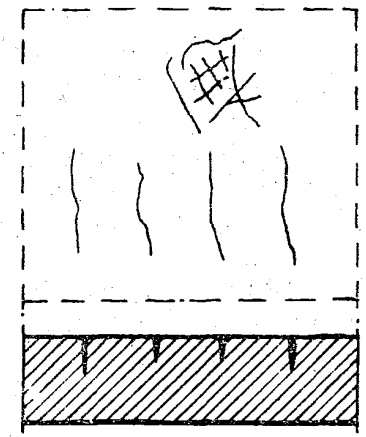

Fig. 4

\section{fisuras de retracción}

La retracción provoca tensiones de tracción cuando se encuentra impedido el libre acortamiento del hormigón. Este impedimento puede deberse a una coacción exterior (apoyos, terreno) o interior (armaduras). Para que la magnitud de la retracción sea lo suficientemente grande como para provocar la fisura han de pasar días, semanas o incluso meses. Estos largos períodos distinguen las fisuras de retracción de las de afogarado.

Cuando se trata de piezas lineales, las fisuras se presentan con trazado perpendicular al eje de la pieza. Un caso típico es el del muro de cimentación, en el que la coacción exterior está representada por el terreno (fig. 5). La fisuración por retracción surge, en general, antes de que se construya el muro de ladrillo encima, ya que éste no experimenta retracción y actúa de elemento de rigidización del muro de hormigón. Si el muro de ladrillo tarda semanas en construirse, es casi seguro que aparecerán las fisuras. Estas suelen surgir cada 10 ó $12 \mathrm{~m}$ y más adelante puede presentarse una segunda familia intermedia, con lo que las fisuras resultan finalmente separadas a unos 5 ó $6 \mathrm{~m}$, con anchura del orden del milímetro o algo superior, como corresponde al valor de la retracción (recuérdese el valor medio de un cuarto de milímetro por metro). Si, como es habitual, existe humedad en el terreno, la parte inferior del muro no retrae (en cualquier caso, siempre retrae menos que la superior) y las fisuras se van cerrando a medida que descienden, hasta desaparecer por completo.

La figura 6 corresponde a un caso poco frecuente, ya que es muy raro encontrar fisuras de retracción en soportes, porque estos elementos suelen tener su extremo superior con libertad de desplaza-

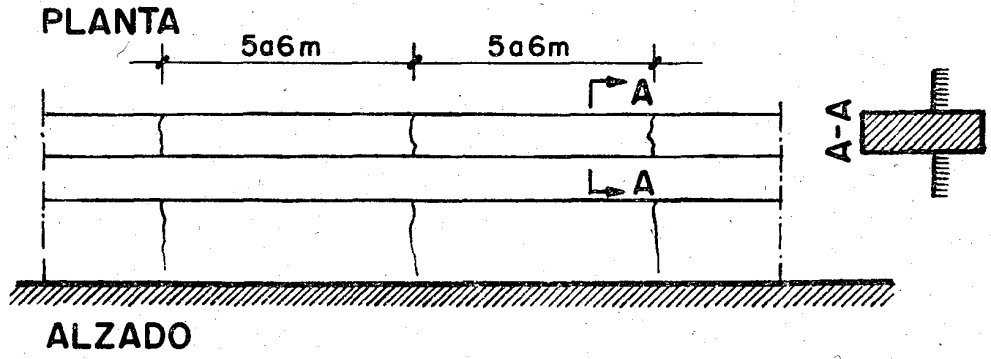

Fig. 5

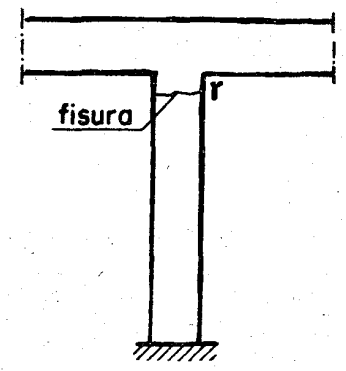

Fig. 6 
miento y, por otra parte, aparecen comprimidos axilmente. A pesar de ello, en soportes poco armados (y poco comprimidos) situados en ambiente muy seco y fabricados con hormigones altos y ricos, puede aparecer una fisura en coronación como la indicada, por ser esta zona la menos comprimida y coincidir, en general, con juntas de hormigonado.

En los elementos de tipo superficial las fisuras de retracción son relativamente frecuentes, especialmente si aparecen asociados con vigas o nervios, que actúan de puntos duros en el conjunto, dada su mayor rigidez. En tales casos (fig. 7) las fisuras aparecen con trazado paralelo a las armaduras y son tanto más numerosas, juntas y finas cuanto mayor es la cuantía (y viceversa, tanto menos numerosas, más separadas y gruesas cuanto menor es la cantidad de armadura). Cuando las placas están coartadas en las dos direcciones principales, la fisuración suele presentarse a inglete, junto a las esquinas.

Las láminas no suelen fisurarse por retracción, a menos que se encuentren fuertemente coartadas en los bordes. Si aparecen, las fisuras siguen trayectorias como las indicadas en la figura 8 , que son las compatibles con las isostáticas de compresión de la lámina.
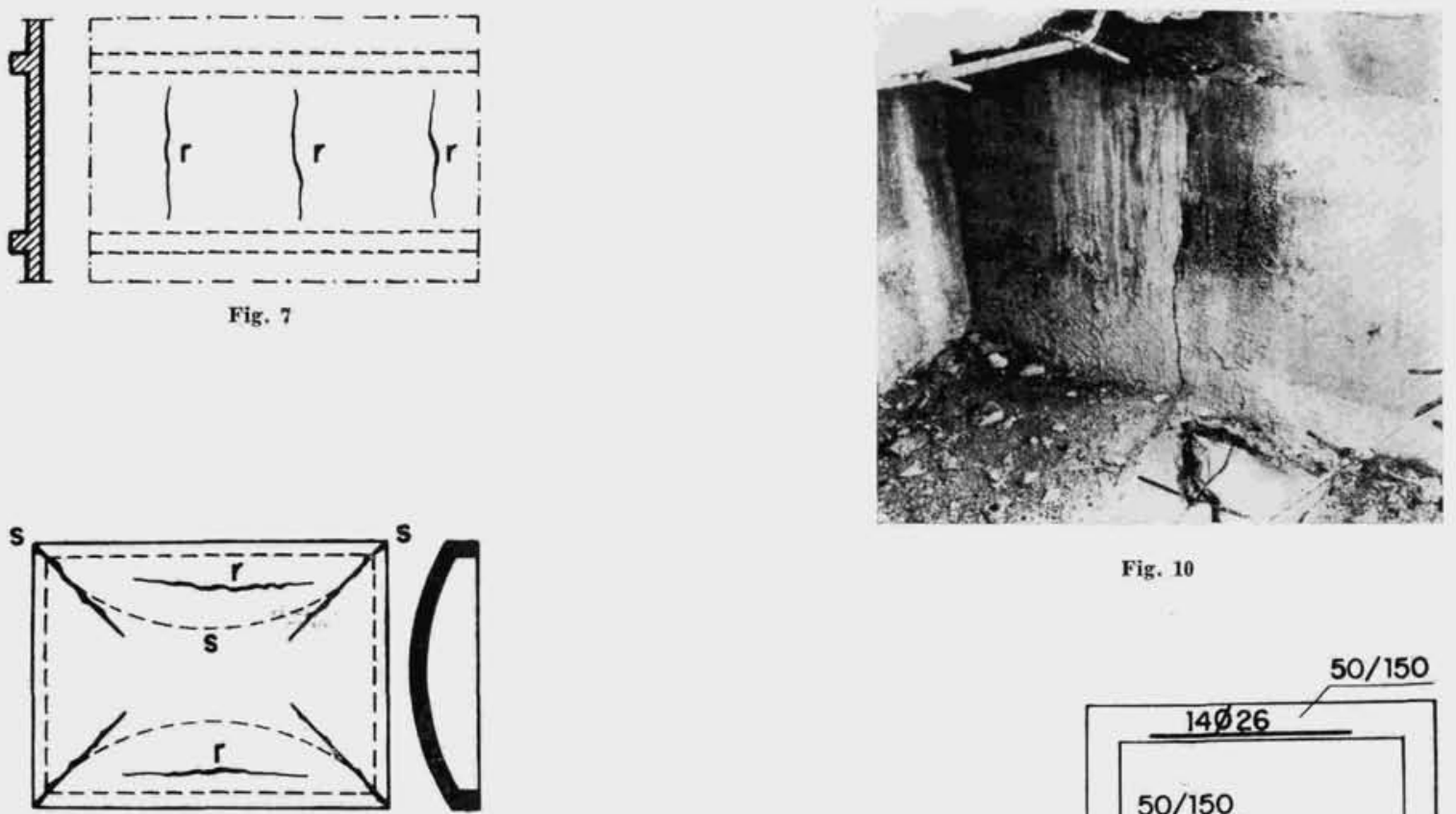

Fig. 10

Fig. 8

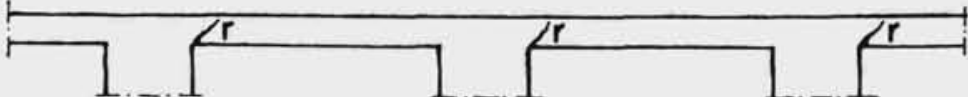

Fig. 9

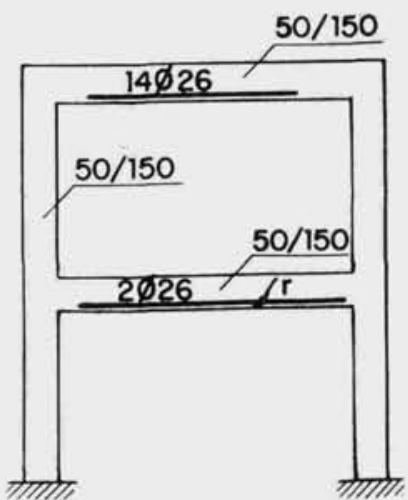

Fig. 11

Es frecuente la fisuración por retracción de vigas, sobre todo si son largas y están fuertemente coartadas en sus extremos. En tales circunstancias, puede salir una fisura aislada en mitad de la luz (ayudada por la flexión provocada por las cargas) o, más probablemente, fisuras junto a los apoyos. Es el caso que se muestra en la figura 9, donde existe gran diferencia de rigidez entre viga y soportes (obsérvese, como nota distintiva, que las fisuras se ubican siempre del mismo lado de los soportes, en forma rítmica). La figura 10 , por su parte, muestra una de estas fisuras en una viga real de un entramado de cubierta, pudiéndose apreciar su anchura constante, dato característico cuando la causa es la retracción. La figura 11 ilustra un caso de comportamiento diferencial, en lo que a retracción se refiere. El dintel superior del pórtico está mucho más armado que el inferior, razón por la cual retrae menos que éste. En consecuencia, el dintel inferior encuentra coacción en sus extremos y se fisura. 
Si la armadura principal de una viga es muy fuerte y su recubrimiento grande, no es raro que éste se fisure por retracción, dado el gradiente que existe entre la superficie libre — donde la retracción es máxima - y la armadura, que impone su coacción al hormigón circundante. Favorece al fenómeno el hecho habitual de que el recubrimiento es mucho más rico en pasta que el corazón de la pieza, a causa del vibrado del hormigón. Si, además, el cemento empleado es de alta categoría y el hormigón es más plástico que seco, la fisuración del recubrimiento es casi segura, a poca sequedad ambiente que exista.

Otro caso característico donde se presentan fisuras por retracción suele ser la parte alta de las paredes de los depósitos de agua, siendo la causa la retracción diferencial entre el hormigón expuesto al aire (que retrae más) y el embebido de agua (que retrae menos o nada). En tales casos, las fisuras desaparecen al llegar al nivel del agua, en forma análoga a la comentada anteriormente para el muro de cimentación.

Fisuras de retracción pueden presentarse también en las almas de las vigas de gran canto y pequeña anchura; en las uniones de elementos de hormigones de distinta edad (vigas en $\mathrm{T}$ y forjados, de rigideces muy diferentes); en las losas largas de pavimentos de hormigón, coartadas en su movimiento por el rozamiento con la base, etc.

Las notas distintivas de las fisuras de retracción podríamos resumirlas así:

aparición retardada (semanas, meses, incluso años);

si hay varios elementos idénticos, las fisuras aparecen sólo en los ubicados en sitio seco y/o ejecutados en tiempo seco y caluroso;

juntas y finas en los elementos muy armados;

separadas y anchas en los elementos poco armados;

separaciones regulares, fisuras rectilíneas, sin ramificaciones;

pequeña anchura, constante en todo el trazado;

rápida estabilización de su anchura.

No siempre es fácil ver una fisura de retracción, dada su finura. Una forma de hacerlas patentes (válida, por otra parte, para cualquier tipo de fisura) es mojar la superficie del hormigón: la fisura absorbe el agua por capilaridad y la retiene después de haberse secado la superficie adyacente.

Medidas preventivas contra las fisuras de retracción serán todas aquellas que eviten los efectos y causas coadyuvantes que se han ido explicando. Unas veces convendrá disponer juntas de retracción (muros de cimentación, pavimentos); otras, disponer armaduras repartidas, mejor de pequeño diámetro, y mejor aún, mallazos (armaduras de piel); otras, en fin, se podrán aceptar las fisuras con mayor o menor filosofía.

Como es obvio, en el momento de establecer la fórmula de nuestro hormigón estamos decidiendo en gran medida, consciente o inconscientemente, su comportamiento con respecto a la retracción. La forma en que influyen los distintos componentes se ha ido comentando más arriba. Este problema puede adquirir una gran importancia, incluso superior al de obtener una cierta resistencia, según el tipo de estructura y el proceso constructivo correspondiente. Para tales casos puede recurrirse al empleo de cementos sin retracción o incluso ligeramente expansivos, como sucede en los problemas de cimentaciones de máquinas, por ejemplo.

Una indicación que puede resultar útil es la de tratar de compensar el acortamiento de retracción con un alargamiento provocado de uno u otro modo, por ejemplo, por elevación de temperatura. En este sentido, el empleo de agua y áridos muy fríos, procurando conservar la temperatura de la masa por debajo de la del ambiente durante el primer período de fraguado, puede resolver alguno de los problemas a que he aludido.

\section{fisuras de origen térmico}

Las dilataciones y contracciones de los elementos de hormigón por causa de la temperatura, sean en valor absoluto o sean diferenciales entre piezas conectadas, son el origen de buen número de fisuras. Quizá el caso más característico de dilatación diferencial sea el de la figura 12, donde se esquematiza el muro de cimentación y primer forjado de una vivienda. En invierno, el muro se acorta con más intensidad que la zapata, por estar ésta enterrada y experimentar, por tanto, un gradiente térmico pequeño. Por su parte, el forjado se acorta aún menos o incluso se dilata, por pertenecer a un interior abrigado, en el que, a menudo, existe calefacción. El resultado es la creación de una serie de tensiones que originan fisuras del tipo de las indicadas, con su máxima anchura en la coronación del muro y que se adelgazan al llegar a la zapata o al ir penetrando en el interior del forjado más caliente. 
Un caso muy parecido es el de los pavimentos de hormigón, cuyas losas experimentan efectos de combado alternativo día-noche (en correspondencia con la mayor dilatación del paramento libre o del enterrado) que pueden fisurar la losa en su mitad. Mucho más claras y previsibles son, en este mismo caso de pavimentos, las fisuras que se producen en las pequeñas obras de fábrica contiguas cuando no se han previsto juntas de dilatación y el pavimento empuja sobre ellas por efecto térmico.

La figura 13 representa un caso que aparece en construcciones industriales. Allá donde un tubo que conduzca agua caliente atraviese un muro de hormigón sin mayores precauciones, éste acabará por fisurarse ante el empuje ocasionado por la dilatación del tubo.

Las chimeneas de hormigón (fig. 14) son un buen ejemplo de elementos sometidos a tensiones de origen térmico. Si entre el refractario y el hormigón no se dispone cámara de aire, el hormigón se fisura. El efecto es máximo en coronación, donde por dilatación diferencial entre el interior y el exterior se producen fuertes tensiones que hay que absorber zunchando fuertemente esta zona.

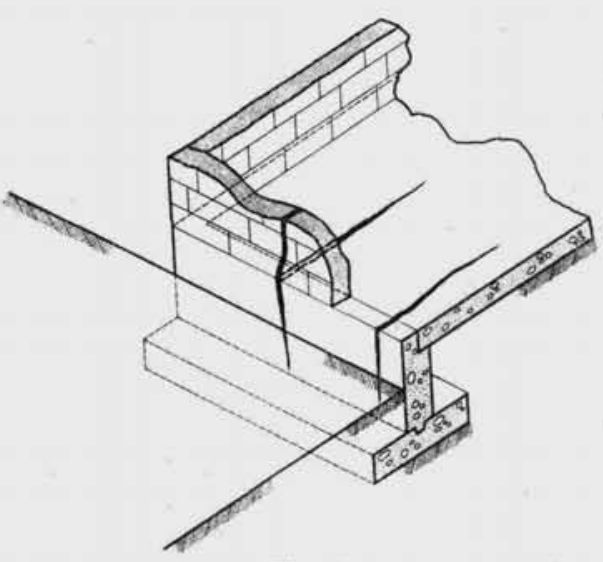

Fig. 12

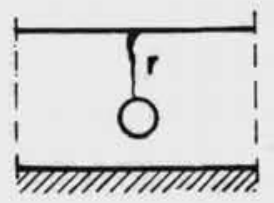

Fig. 13

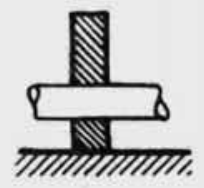

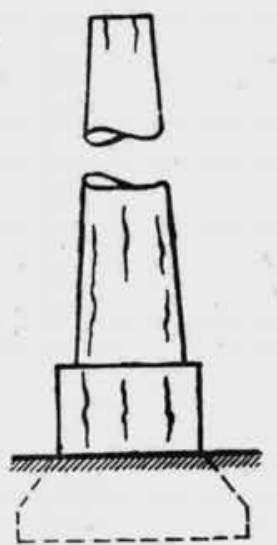

Fig. 14

La contracción producida por un descenso de temperatura es análoga a la originada por retracción, y ambos efectos se suman a menudo, siendo difícil a veces distinguir uno de otro. Existe, no obstante, la diferencia esencial de que, en el primer caso, los dos materiales hormigón y acero se deforman por igual (la diferencia entre sus coeficientes de dilatación es despreciable) y no surgen tensiones entre ellos, al contrario de lo que sucede con la retracción.

Cabe recordar aquí, en fin, el efecto expansivo del hielo como origen de fisuras y deterioros: congelación del agua en depósitos de paredes verticales, en agujeros de anclaje situados en la periferia de bloques de hormigón, etc., etc.

\section{fisuras por corrosión de armaduras}

Las armaduras están protegidas del exterior por el hormigón que las rodea, y es en la basicidad de éste donde reside la seguridad de aquéllas. El oxígeno del aire, el anhídrido carbónico y el agua, por no citar más que tres agentes comunes, atacan al hierro y lo oxidan, a una velocidad tanto mayor cuanto más ácido es el medio. Si el hormigón es más o menos poroso, su cal va siendo carbonatada fácilmente por el $\mathrm{CO}_{2}$ del aire, con lo que el $\mathrm{pH}$ del hormigón, cuyo valor normal es del orden de 12 a 13, puede bajar hasta 8 , colocando al acero en precarias condiciones de defensa.

El volumen del óxido al formarse es unas ocho veces mayor que el del metal que lo origina, lo que provoca fisuras y, más adelante, el desprendimiento del hormigón circundante. En general, las fisuras de corrosión tienen el mismo trazado que la armadura principal, tanto en pilares como en vigas (fig. 15), y es frecuente que aparezcan manchas de óxido según el mismo trazado. Por consiguiente, una fisura paralela a las barras principales debe ser motivo de alarma fundada.

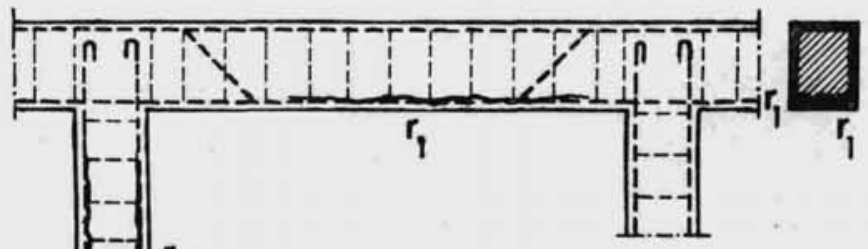

$r_{2}$

Fig. 15 
La mejor protección contra estos efectos es un recubrimiento bien compacto y de suficiente espesor. A igualdad de las restantes variables, el espesor del recubrimiento influye en la durabilidad elevado al cubo (Joisel), es decir, que un recubrimiento doble proporciona una protección ocho veces más eficaz. Se comprende que si el hormigón es poco compacto o poroso, lo dicho no tiene sentido, ya que la eficacia del recubrimiento es entonces prácticamente nula cualquiera que sea su espesor.

\section{fisuras debidas a la acción de las cargas}

Bajo la acción de las cargas exteriores, los elementos de hormigón pueden verse sometidos a tracción, a compresión, a flexión, a esfuerzo cortante o a torsión, y cada uno de estos estados tensionales entraña un tipo de fisuración diferente.

La tracción axil, poco frecuente en piezas de hormigón armado, origina numerosas fisuras de trazado normal a las barras principales, atravesando la sección de una parte a otra (fig. 16). Las fisuras se forman más o menos simultáneamente y suelen ubicarse en los lugares de emplazamiento de los estribos.

La compresión axil provoca diferentes formas de fisuración, según la esbeltez del elemento y el grado de coacción transversal que tenga en sus extremos. Ambos efectos se observan bien en los ensayos de laboratorio, con probetas sencillas. Si no existe rozamiento alguno entre las caras de la probeta y los platos de la prensa (cosa bien difícil de conseguir) la compresión pura ejercida sobre aquélla la rompe por formación de columnillas paralelas a la dirección del esfuerzo (fig. 17 a). Si hay rozamiento, éste coarta la dilatación transversal de la probeta y el esquema de fisuración es más o menos parecido al de la figura $17 \mathrm{~b}$.

Con piezas más esbeltas, intervienen nuevos factores, tales como una posible heterogeneidad del hormigón a lo largo de la pieza, un reparto no uniforme de las compresiones, etc., obteniéndose diversos esquemas de fisuración (fig. 18). La figura 19, por su parte, nos muestra una fisuración muy peligrosa: fisuras finas y juntas en una cara de un soporte esbelto, a la mitad de su luz, que significan con certeza casi absoluta que se está cerca del pandeo del elemento.

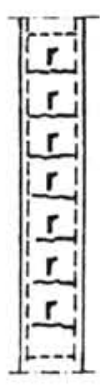

Fig. 16

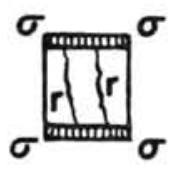

Fig. 17 a

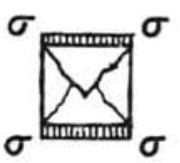

Fig. 17 b
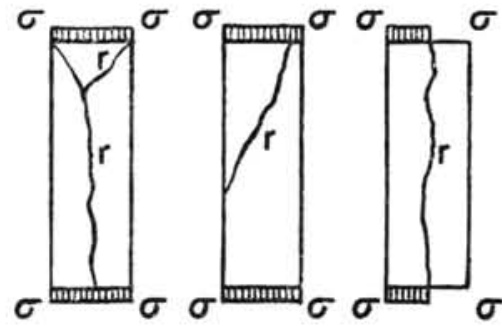

Fig. 18

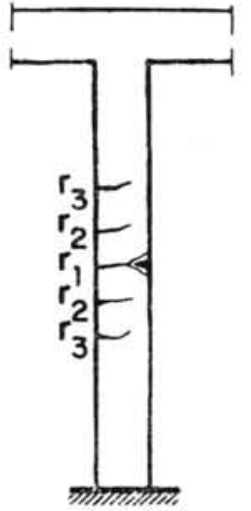

Fig. 19

En general, las fisuras verticales en soportes son signo de catástrofe inminente por aplastamiento del hormigón. Si el soporte está zunchado, salta primero el recubrimiento y la pieza puede seguir resistiendo, pero con grandes deformaciones que, en general, no pueden ser soportadas por los elementos horizontales ligados al soporte.

Las fisuras de flexión son las más conocidas. La figura 20 a muestra una fisuración típica en la zona de tracción de un pórtico. Si el fenómeno progresa, puede alcanzarse el esquema 20 b, que corresponde a un agotamiento inminente (y brusco) del hormigón en compresión.

La figura 21 se refiere a una viga e ilustra la fisura típica de flexión (a) y de esfuerzo cortante (b). En el primer caso, la fisura se inicia en la armadura, progresa un poco en vertical hacia el eje neutro y se incurva luego más o menos, buscando el punto de aplicación de la carga y deteniéndose al alcanzar la cabeza de compresión. Esta fisura avisa con mucho tiempo. 
Por el contrario, las fisuras de cortante pueden comenzar en el alma, progresar hacia la armadura y llegar luego hasta la carga, dividiendo en dos partes la pieza. Este proceso puede ser muy rápido, e incluso instantáneo, dependiendo de la cuantía de armadura transversal existente. De ahí su gran peligrosidad.

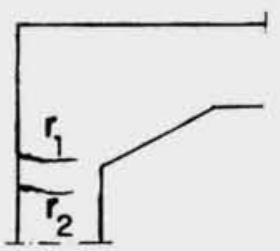

Fig. 20 a

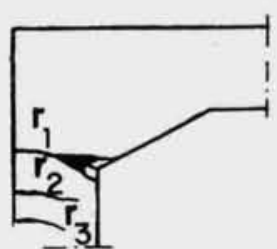

Fig. 20 b
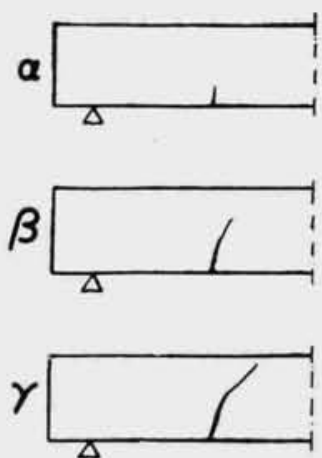

Fig. 21 a
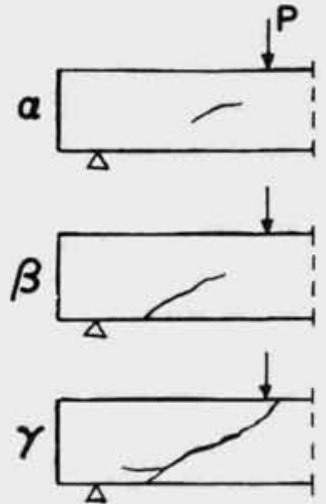

Fig. 21 b

En la figura 22 se aprecia una fisura de esfuerzo cortante correspondiente a una viga real, mostrando su buzamiento inclinado típico. Y los esquemas de la figura 23 nos recuerdan zonas típicas de vigas en $\mathrm{T}$ donde pueden presentarse fisuras por esfuerzo cortante.

En cuanto a la torsión, su efecto produce una red de fisuras a $45^{\circ}$ según el esquema de la figura 24 . Los efectos de torsión se olvidan a veces, sobre todo en estructuras sencillas del tipo de las de edificación, en las cuales puede suceder que crujías adyacentes de luz muy descompensada provoquen torsiones importantes en la viga correspondiente. En estos casos, si no se han previsto los cercos suficientes, aparecerán fisuras del tipo de las indicadas.

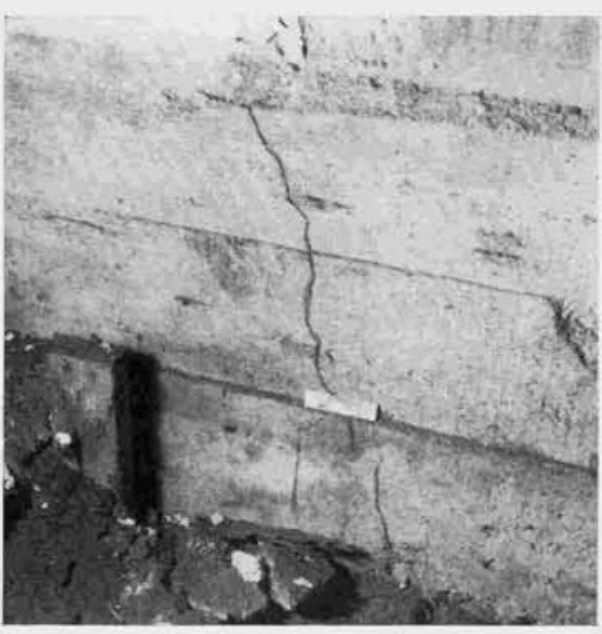

Fig. 22
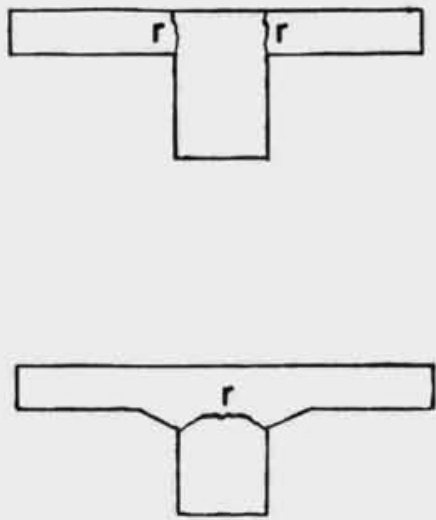

Fig. 23

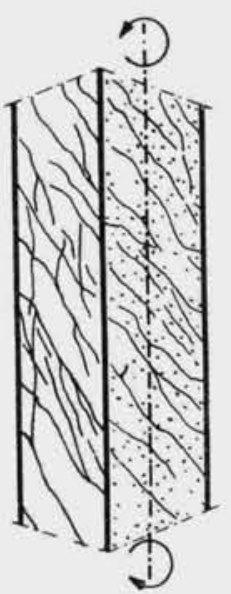

Fig. 24

Como resumen podemos recordar las características principales de las fisuras de flexión:

- no afectan a todo el canto, sino que se detienen en la fibra neutra;

- aparecen siempre varias y bastante juntas, especialmente si el acero es de alta adherencia;

- aparecen bajo carga y desaparecen al retirar ésta;

- son perpendiculares al eje de la pieza y se inclinan luego más o menos según el valor del esfuerzo cortante. 


\section{fisuras debidas a errores de proyecto o ejecución}

Veremos ahora unos cuantos ejemplos de fisuras más o menos habituales que se deben a descuidos o errores en el proyecto o durante la ejecución.

La figura 25 corresponde al caso de concentración excesiva de ganchos de anclaje en una misma sección. En tales casos, el esfuerzo que debe soporiar el hormigón es demasiado grande y éste se fisura a $45^{\circ}$ por desgarramiento. Para evitarlo, deben decalarse las secciones de anclaje y, si todavía resulta una cierta concentración, envolver los ganchos con barras finas transversales que «cosan» la eventual grieta, tomando las acciones tangentes que ahí se desarrollan $\left({ }^{*}\right)$.

Otra zona singular corresponde a las cartelas de las vigas asociadas a soportes. Si el cartabón se arma débilmente, pueden aparecer las fisuras indicadas en la figura 26.

La figura 27 muestra dos defectos en articulaciones de hormigón. Si la armadura transversal se detiene demasiado pronto, puede aparecer la fisura indicada en a; y si dicha armadura no llega a los extremos, como debe ser, pueden degollarse las esquinas, como se muestra en b.

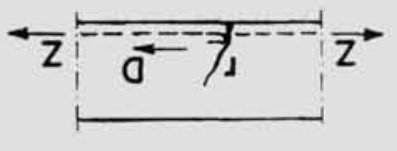

Fig. 25

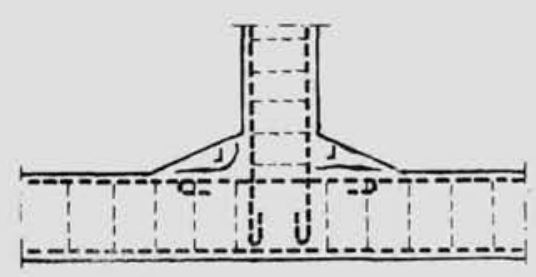

Fig. 26

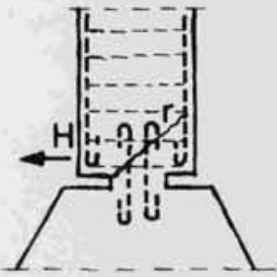

Fig. 27 a

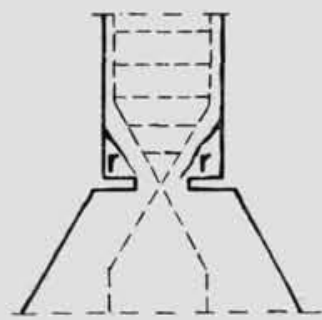

Fig. 27 b

En la figura 28, un defecto relativamente frecuente en las ménsulas de apoyo. Si el apoyo no se dispone bien destacado, o no existe, la viga degüella a la ménsula al entrar en carga y girar, ya que en lugar de un apoyo se tiene un empotramiento con un cierto momento cuyo brazo es muy corto, lo que significa que la fuerza sobre el voladizo es muy fuerte.

Dentro de los errores de ejecución, la figura 29 representa el caso en que las armaduras se han detenido antes de llegar al extremo, lo que conduce siempre a una fisura como la indicada. Más frecuente y peligroso es el caso en que, durante el hormigonado, se caen los cercos de un soporte (fig. 30), lo que coloca a éste en situación muy grave, delatada por fisuras verticales como las indicadas. Igualmente frecuente y peligrosa es la caída de la armadura en un voladizo, lo cual da, en el mejor de los casos, una fisura como la de la figura 31 ; y en el peor, la caída completa del elemento, que gira $90^{\circ}$ sobre la armadura desplazada, actuando como charnela, tal y como muestran las fotografías 32 y 33, correspondientes a un balcón siniestrado hace poco tiempo en la provincia de Murcia.

Por terminar con los ejemplos relativos a faltas en la ejecución, señalaremos el caso un poco inocente de cedimiento del encofrado (fig. 34), que produce fisuras prematuras cuyo origen puede confundirse si se olvida considerar, entre las posibilidades objeto de análisis, este defecto de construcción.

(*) Véase al efecto la teoría francesa del profesor Robinson llamada "regla de las costuras». 


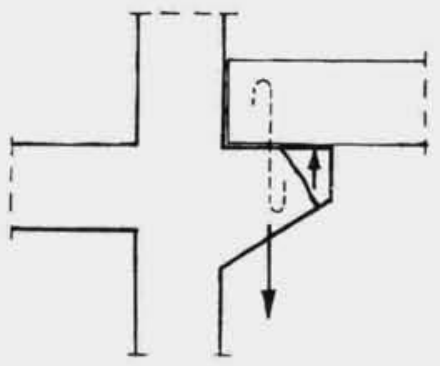

Fig. 28

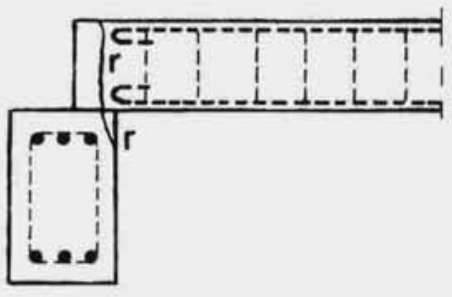

Fig. 29

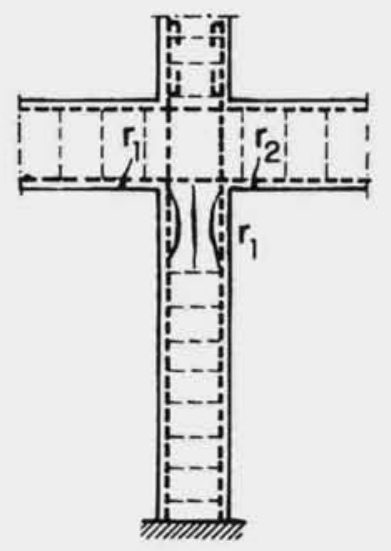

Fig. 30

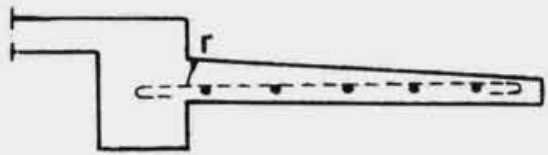

Fig. 31

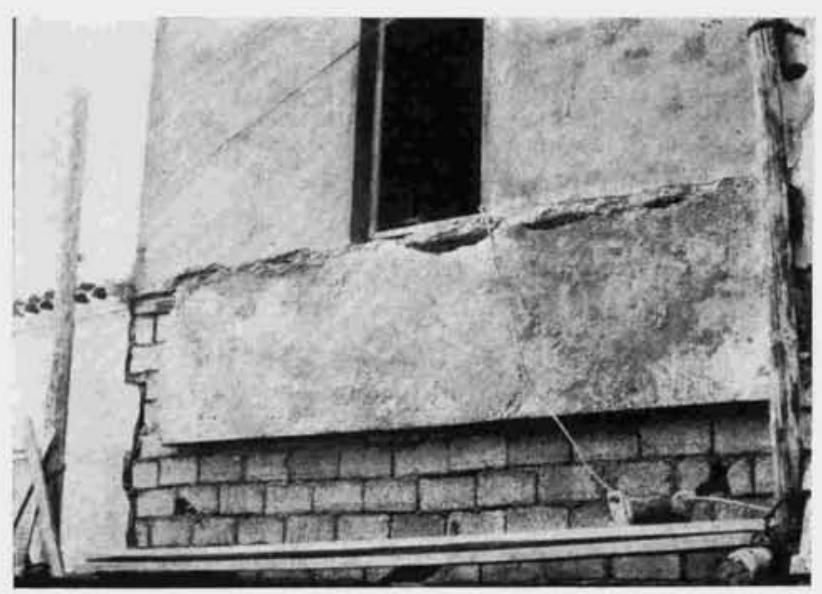

Fig. 32
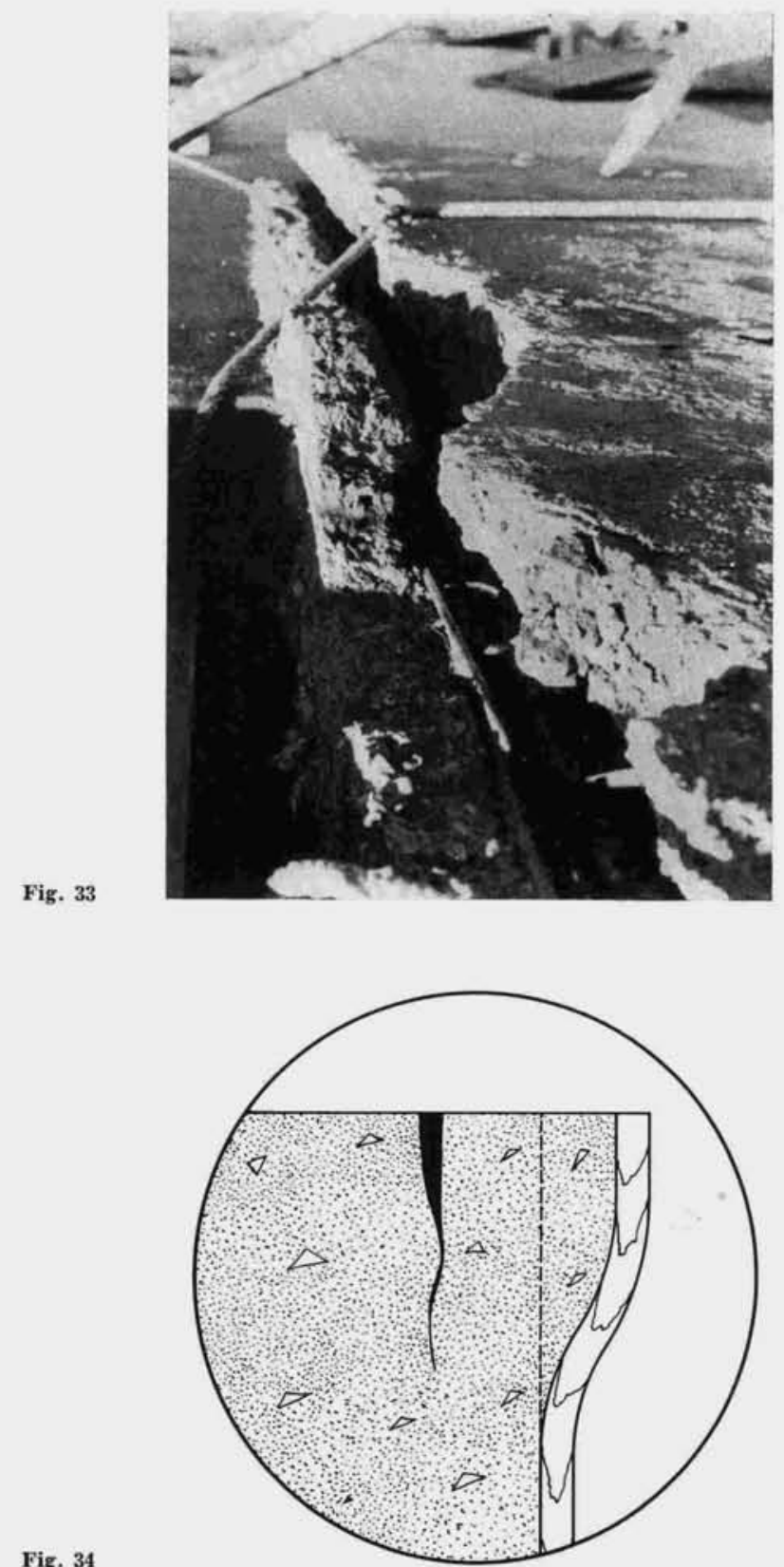


\section{vigilancia de fisuras}

Un dato que suele ser imprescindible para conocer la causa de una fisura y calificar su grado de peligro, es el de si la fisura está viva o no. O dicho de otro modo, si su anchura y longitud se van modificando con el tiempo o si, por el contrario, están prácticamente estabilizadas. Para obtener dicho dato, puede ser útil cualquiera de los procedimientos simples que se ilustran en la figura 35 .

El primero consiste en marcar con una cruz el extremo de la fisura, para poder comprobar más tarde si ha progresado. El segundo consiste en encajar un palillo o aguja en la hendidura, que caerá si ésta ensancha. El tercero, algo más completo, es colocar un testigo entre los labios de la fisura. Si se emplea papel o tela fina, es posible conocer no sólo los aumentos, sino también las disminuciones de anchura; pero ambos materiales tienen el inconveniente de ser muy sensibles a la humedad ambiente, lo que puede falsear los resultadus. Es preferible utilizar testigos de yeso muy finos, de no más de dos o tres milímetros de espesor, que acusan perfectamente, partiéndose, cualquier movimiento en más de la fisura.

El cuarto procedimiento es el más riguroso y consiste en colocar dos referencias fijas a ambos lados de la grieta, midiendo su distancia con precisión. Como referencias suelen utilizarse dos plaquitas de metal con un rehundido central semiesférico, donde encajan las patas de un elongámetro que aprecia centésimas de milímetro. Las plaquitas se pegan con resinas epoxi.
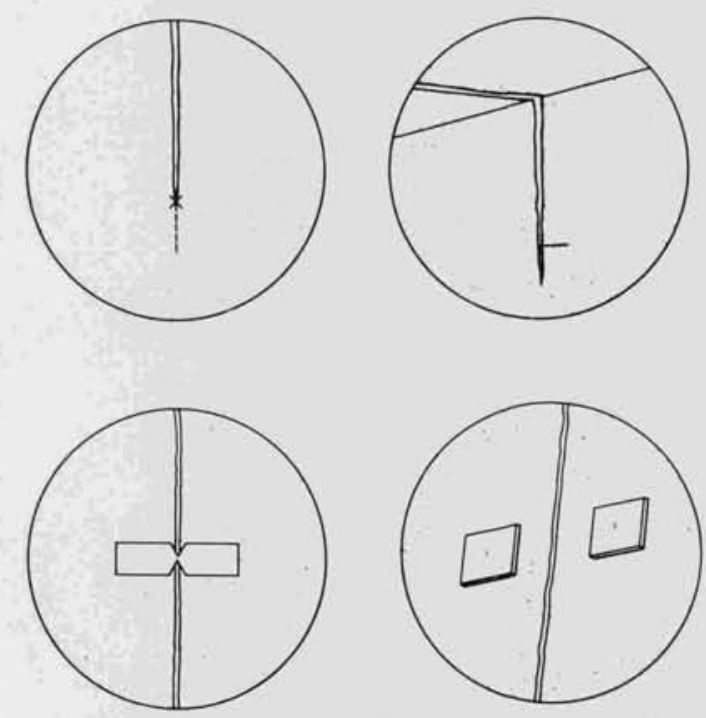

Fig. 35

\section{causas}

Hemos visto que las causas que pueden originar fenómenos patológicos en el hormigón son muy variadas, y los ejemplos que se han comentado no agotan el tema. A continuación se indica una relación de causas más frecuentes de degradación, tratando de sistematizarlas:

\section{Previas a la ejecución:}

1. Defectos de proyecto:

a) errores de cálculo;

b) errores de dibujo;

c) errores en la evaluación de las cargas;

d) errores en la concepción de detalles:

d.1. recubrimientos, anclajes y empalmes de barras mal concebidos,

d.2. nudos y uniones de piezas insuficientemente estudiados,

d.3. ángulos entrantes, variaciones bruscas de sección, etc., mal concebidos,

d.4. juego insuficiente de juntas de dilatación,

d.5. desagües insuficientes o mal dispuestos, d.6. tensiones tangentes no previstas,

d.7. incompatibilidad de materiales,

d.8. olvido de los efectos de retracción y fluencia.

2. Defectos de materiales:

a) cementos:

a.1. calor de fraguado $y / 0$ retracsión excesivos,

a.2. expansión excesiva,

a.3. fraguado defectuoso,

a.4. resistencias insuficientes,

a.5. otras irregularidades fuera de Pliego;

b) áridos:

b.1. terrones de arcilla,

b.2. finos en exceso,

b.3. materia orgánica. 
b.4. contenido en compuestos de azufre,

b.5. reactividad árido-álcali,

b.6. áridos heladizos,

b.7. coeficiente de forma inapropiado,

b.8. otras irregularidades;

c) agua:

c.1. acidez excesiva,

c.2. exceso de sustancias disueltas,

c.3. contenido en sulfatos,

c.4. contenido en ion cloro,

c.5. materia orgánica,

c.6. otras irregularidades;

d) adiciones;

e) armaduras:

e.1. suciedad,

e.2. óxido no adherente,

e.3. otras irregularidades;

f) hormigones:

f.1. granulometría defectuosa,

f.2. dosificación inadecuada (exceso de agua),

f.3. otras irregularidades.

\section{Durante la ejecución:}

1. Defectos de encofrado:
a) asientos;
b) desplazamientos;
c) juntas mal concebidas;
d) suciedad.

2. Defectos de hormigonado:
a) mala compactación;
b) segregación;
c) otros defectos.

3. Defectos de protección en las primeras edades:
a) afogarado;
b) helada.

4. Defectos de curado:

a) curado insuficiente;

b) empleo de aguas perjudiciales (agua de mar).
5. Defectos de desencofrado:

a) desencofrado prematuro;

b) uso de procedimientos inadecuados.

6. Defectos en juntas de hormigonado:

a) mala orientación;

b) falta de adherencia.

7. Defectos en la ejecución de detalles (ver I.1.d).

\section{Posteriores a la ejecución:}

1. Retracción.

2. Tensiones de origen térmico:

a) variaciones de la temperatura atmosférica;

b) variaciones de la temperatura interna.

3. Absorción de agua por el hormigón.

4. Corrosión de armaduras:
a) debida a agentes químicos;
b) debida a efectos electrolíticos;
c) corrosión bajo tensión;
d) otras causas.

5. Reacciones químicas o alteraciones atmosféricas:
a) helada;
b) sales de deshielo;
c) agresivos químicos.

6. Erosión y abrasión.

7. Impactos, ondas de choque, acciones imprevisibles.

8. Tensiones originadas por las acciones:

a) de cargas o acciones directas:
a.1. permanentes,
a.2. sobrecargas;

b) de acciones indirectas:
b.1. fluencia,
b.2. asientos del terreno,

b.3. sismos:

9. Incompatibilidad de deformaciones. 


\section{ejemplos}

Para ilustrar la relación de causas apuntada, comentaremos a continuación algunos ejemplos:

La figura 36 se refiere al error de proyecto ya clásico en que se coloca una armadura continua de tracción junto a un paramento quebrado: al entrar en carga, la armadura tiende a hacer saltar el recubrimiento. Para evitar este efecto, deben despiezarse convenientemente las barras o sujetarse con los cercos o estribos necesarios, teniendo en cuenta en este último caso que esta armadura transversal requiere de una cierta deformación para entrar en trabajo, cuya compatibilidad hay que estudiar.

En la figura 37 se han esquematizado dos tipos de errores. El primero se refiere a la junta A del tablero con el estribo, que debía de estar totalmente libre. Si no es así, el tablero arrastrará en su movimiento al muro, decapitándolo en la forma indicada.

El segundo, más grosero, se refiere al caso en que se coloca una armadura transversal insuficiente en un dado de apoyo. En estos casos, además, debe preverse la transmisión de un cierto esfuerzo horizontal a través del aparato de apoyo, ya que el funcionamiento de éstos nunca es igual al teórico para el que están previstos.

La figura 38 muestra el efecto que producen las cargas concentradas en los bordes de las losas de hormigón. Puede presentarse el caso en los puentes de ferrocarril en que un tablero de losas de hormigón reciba las traviesas. Si alguna de éstas va ubicada en un borde de losa, ésta acaba fisurándose.

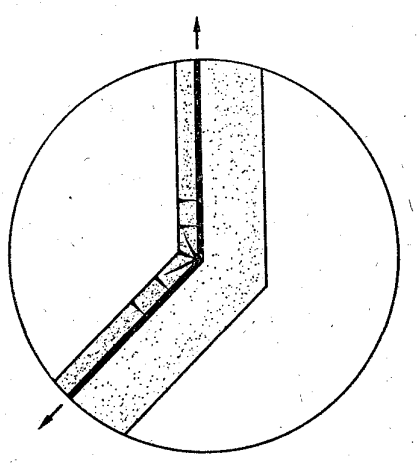

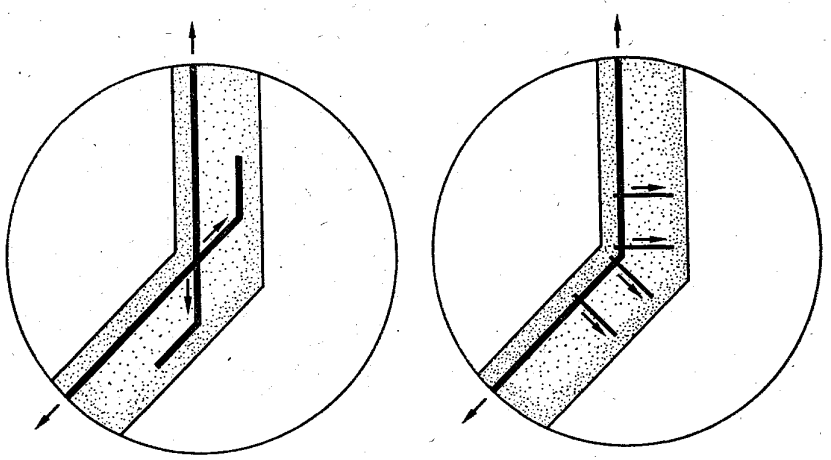

Fig. 36

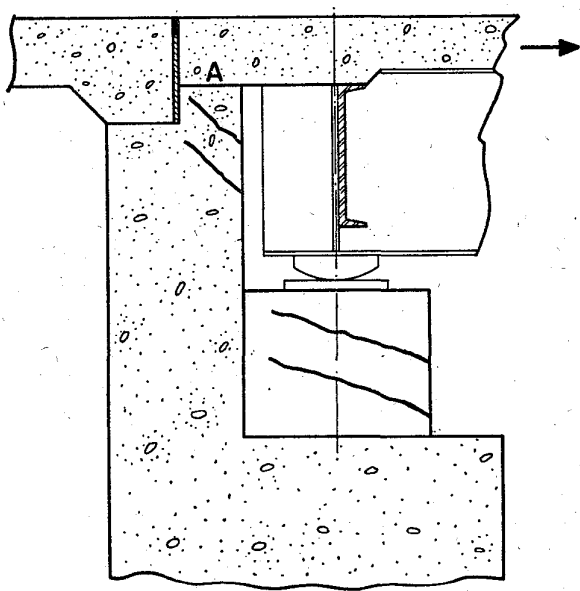

Fig. 37

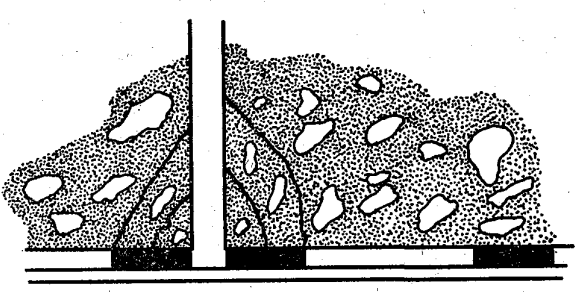

Fig. 38

Las deformaciones no compatibles son origen de un sinnúmero de fisuras en toda clase de elementos constructivos. Tomemos el caso sencillo de un dintel, para el que se admite una flecha en servicio de $1 / 300$ a $1 / 400$ de la luz. Si el dintel tiene $6 \mathrm{~m}$ de luz, eso significa de $1,5 \mathrm{~cm}$ a $2 \mathrm{~cm}$, deformación ésta (fig. 39) que puede no admitir un muro de ladrillo que vaya sobre él. Si además carga un forjado, éste baja también y puede fisurar los tabiques que soporta. Y si se tiene en cuenta, además, el efecto de las deformaciones lentas bajo la carga permanente, que puede suponer fácilmente del doble al triple de la flecha inicial, se comprenderá que sea tan frecuente encontrar muros de ladrillo y tabiques fisurados. O partidos, si se trata de elementos de cristal. 
Las soluciones al problema anterior pueden ser varias. O actuar por vía de otorgar mayor rigidez y resistencia al muro (lo que no suele ser aconsejable) o actuar por la vía contraria, es decir, dotar al muro de mayor plasticidad para conseguir que admita mayores deformaciones sin romper; para ello, se puede jugar con el mortero de agarre. Por otra parte, y siempre que sea posible, convendrá ejecutar estos tabiques después de haber entrado en carga los dinteles (ir tabicando una vivienda de arriba a bajo y no al contrario) o, al menos, dejar sin colocar la última hilada, que se retaca posteriormente.

La misma causa de deformaciones incompatibles no previstas produce la fisuración de los revestimientos que hayan podido colocarse en forjados que reciben apeos, cuando al retirarse éstos varía la deformada de aquéllos. El tema es variadísimo.

En la figura 40 se da un ejemplo de solidarización indebida de dos elementos cuya estabilidad y buen comportamiento independiente había sido impecable. Al entrar en carga la bóveda V, el empuje horizontal resultante vuelca la viga de borde. El hecho ocurrió en Francia, hace ya bastante tiempo.

Entre los ejemplos de desagües mal organizados cabe citar el caso del tablero de puente en el que se dispone un imbornal, con caída libre del agua, en las proximidades de un aparato de apoyo. En tal caso, el viento puede proyectar el agua contra él, oxidándolo o perjudicándolo de alguna manera. La solución consiste, evidentemente, en ubicar el desagüe en otro sitio o, mejor todavía, en disponer una canalización a lo largo de la pila, para llevar el agua hasta el suelo.

Un caso curioso de fallo se muestra en la figura 41, correspondiente a un muro de contención de tierras que se cayó nada más entrar en carga. Sucedió en Nueva York el año 1950 y la causa fue un error en la interpretación del plano, al haberse dispuesto barras de $1 / 4$ de pulgada en vez de $1 \frac{1 / 4}{4}$ de pulgada, debido a la coincidencia del 1 con una línea de cota. También en Estados Unidos (Colorado, año 1954) se produjo el fallo de unos pórticos de hormigón armado, por causa de una mala ejecución de la ferralla (fig. 42). Se dispuso un empalme de barras por solapo en una zona crítica y la rotura sobrevino en la forma indicada en la figura.

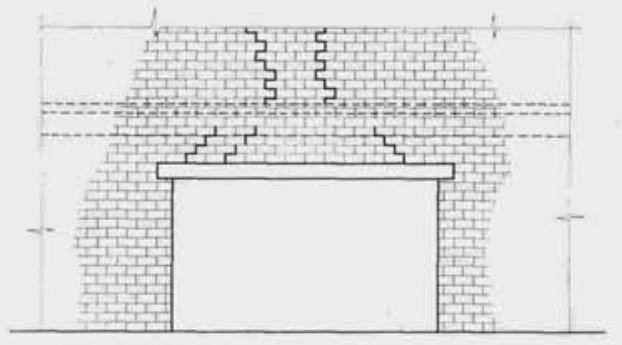

Fig. 39

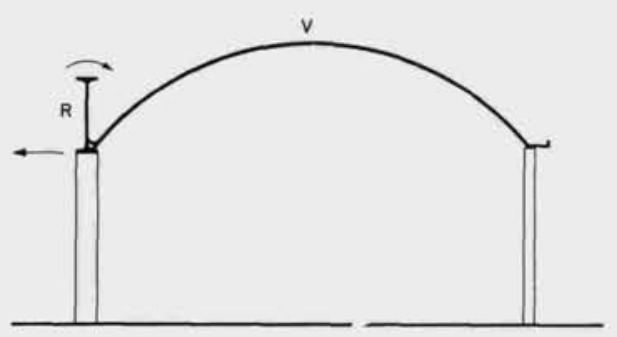

Fig. 40
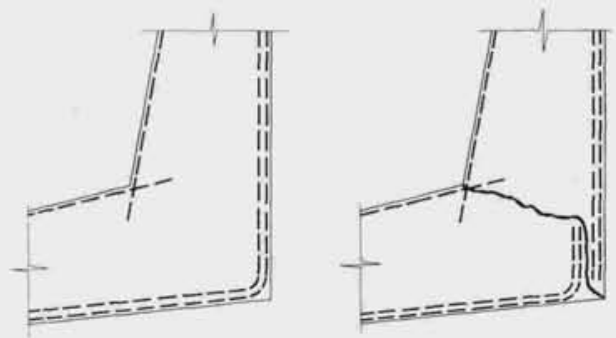

Fig. 42

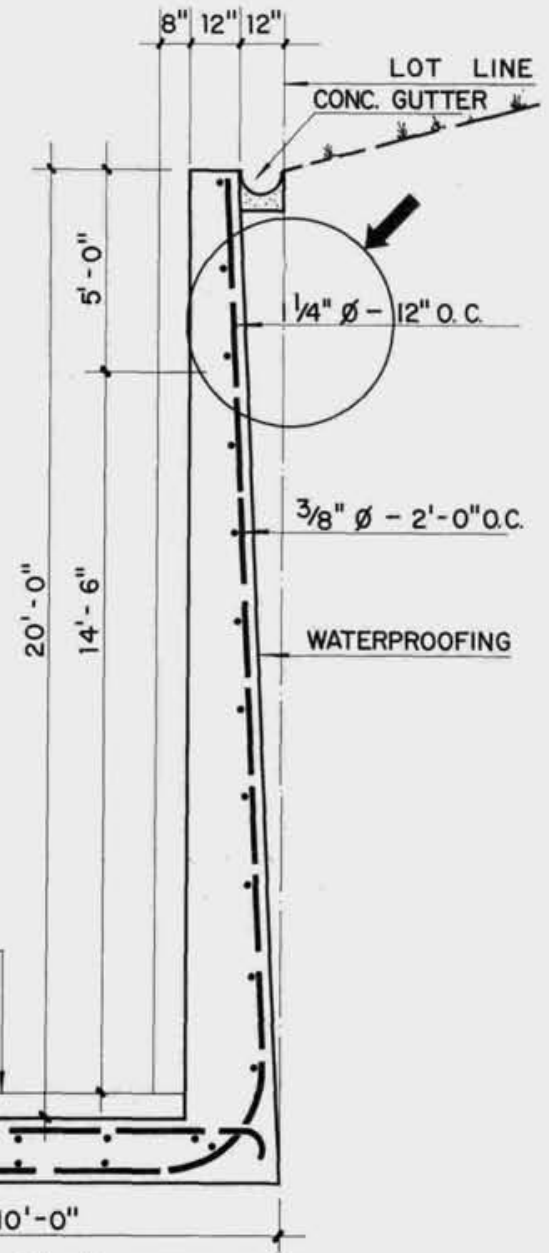

Fig. 41 
La fotografía 43 corresponde a la cara superior de una zapata de puente y muestra una fisuración abundante en piel de cocodrilo. Los testigos extraídos (fig. 44) denotaron que la profundidad de las fisuras era apreciable. Se investigó en este caso - en el que intervino recientemente el Instituto Eduardo Torroja - toda una serie de posibles orígenes de anomalías, comenzando por un análisis

Fig. 43

Fig. 44

Fig. 45
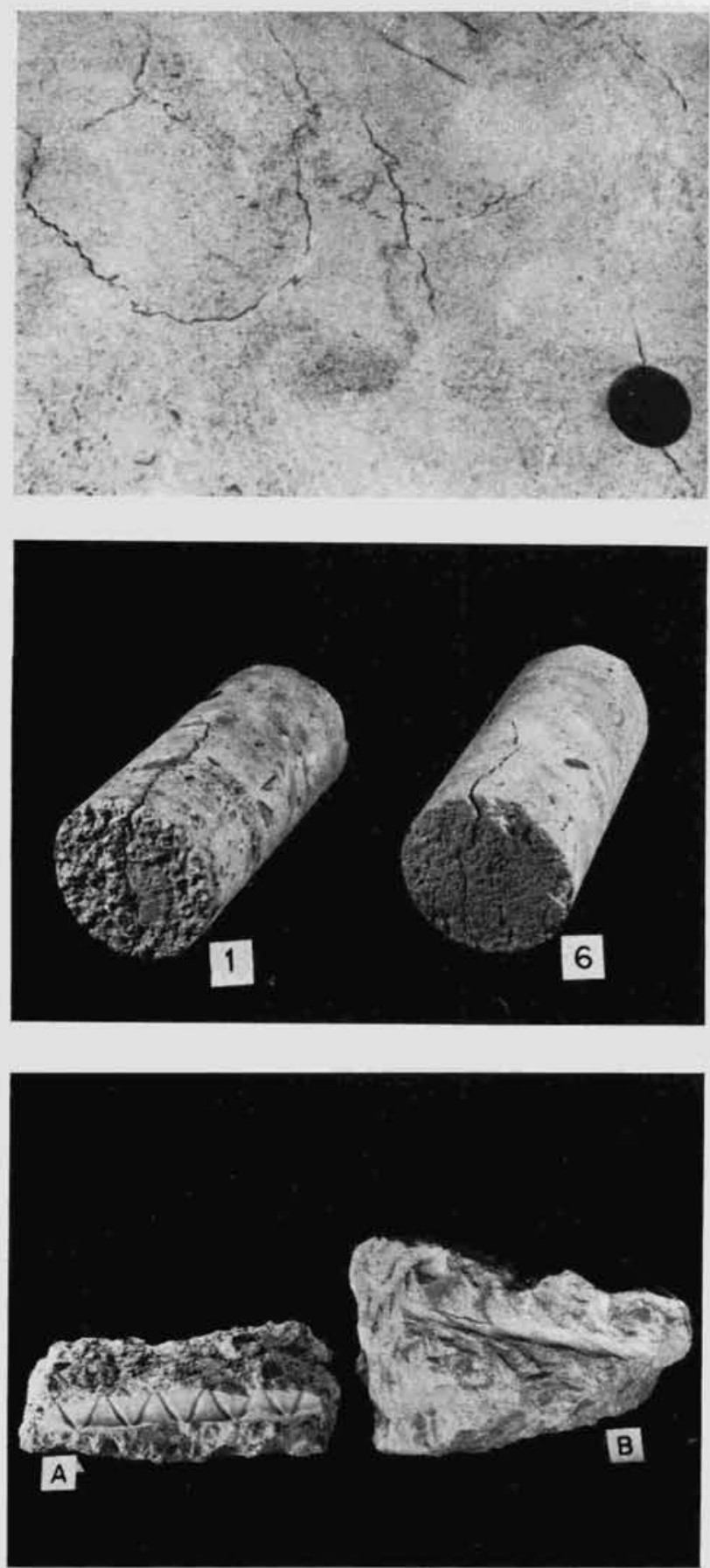

Fig. 46 Fig. 47
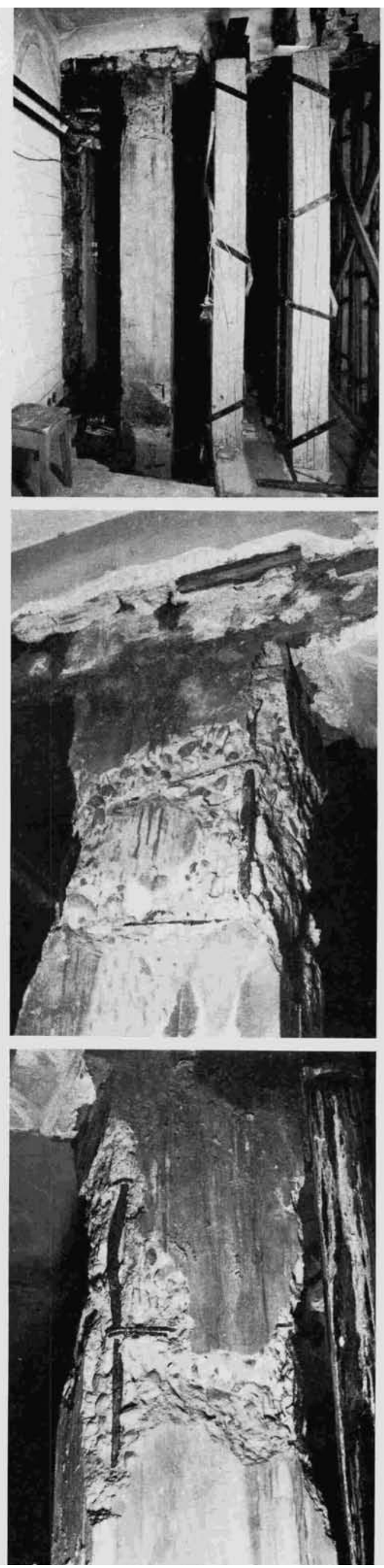
a fondo del cemento, que es siempre el primer presunto culpable en casos de este tipo. Como tantas veces ocurre, no era aquí el cemento la causa de las irregularidades, sino, fundamentalmente, el exceso de contenido en finos que tenían los áridos. Dicho exceso producía una pasta en el hormigón muy susceptible a la retracción y con poca adherencia al árido grueso, lo que colocaba al material en condiciones especialmente vulnerables.

La figura 45 muestra las huellas que deja una barra de adherencia mejorada sobre el hormigón. Contra lo que pudiera pensarse a primera vista, estas huellas tan nítidas no significan nada en contra del hormigón, ya que el efecto de la vibración produce un enriquecimiento en pasta de las zonas vecinas a las barras y a ello se debe la perfección del dibujo. En la fotografía se muestran dos hormigones, uno de los cuales (A) era sospechoso, y el otro (B) no lo era. Como puede observarse, ambos muestran el mismo aspecto en lo relativo a huellas del acero sobre su masa.

Las figuras 46, 47 y 48 muestran el aspecto de un pilar próximo a su agotamiento resistente. Como se ve, ha saltado el recubrimiento en algunas zonas y la armadura principal aparece pandeada entre los puntos de sujeción a los estribos. Estas fotos son un buen recordatorio de la limitación de cálculo que establece la Instrucción vigente E.H. 68 en el sentido de no contar como resistencia del acero en compresión un valor superior a $4.000 \mathrm{kp} / \mathrm{cm}^{2}$. Dicho valor corresponde a una deformación del 2 por 1.000, que es la de rotura del hormigón a compresión simple. De nada habría servido que las barras del pilar en cuestión hubiesen tenido un límite elástico superior al valor indicado, ya que el exceso no habría podido aprovecharse.

La fotografía 49 corresponde a un paso superior en la Nacional IV, cuyo gálibo estricto ha ido disminuyendo por la colocación de sucesivas capas de refuerzo en el firme. El resultado es que algunos camiones sobrecargados producen fuertes impactos en las vigas, especialmente en la de borde, habiendo llegado a dejar al descubierto la armadura en una zona relativamente amplia (fig. 50). Se comprobó la buena-disposición de los $\operatorname{cer} \cos$ y, a pesar de que el alma aparecía abundantemente fisurada verticalmente debido a los impactos, se concluyó que la capacidad resistente del elemento no había disminuido prácticamente. En casos análogos, por tanto, basta con reparar los desperfectos con la aplicación simple de un mortero que proteja las armaduras. Conviene que el mortero sea a base de resinas epoxi para asegurar su buena unión y resistencia.

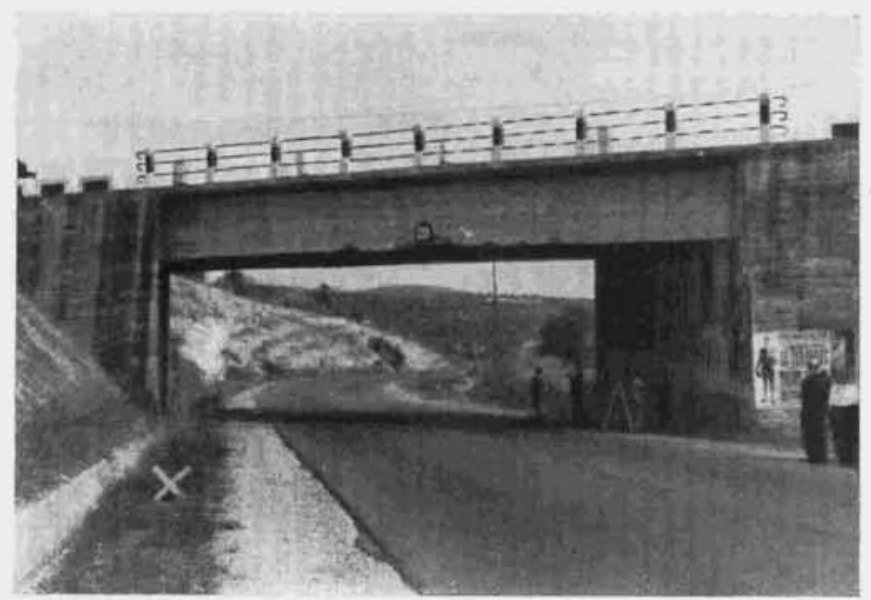

Fig. 49

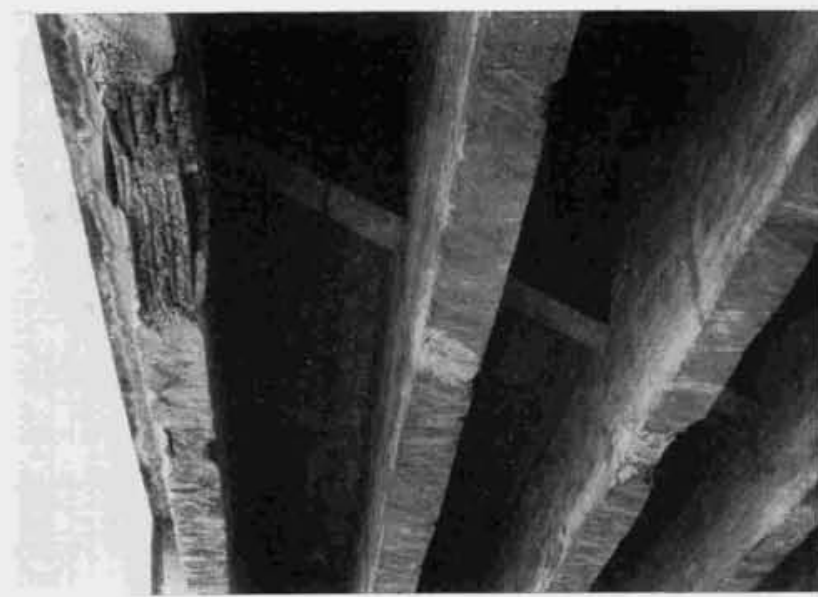

Fig. 50

El ejemplo indicado da entrada a un par de ideas sobre reparación de fisuras. La primera y principal es que nunca debe taparse una fisura sin haber estudiado antes la causa que la produjo y estar bien seguros de que dicha causa no volverá a actuar después, ya por desaparición del agente, ya por haberse adoptado las disposiciones convenientes para que no perjudique de nuevo. La segunda idea es que un mortero de cemento no es lo más indicado para reparar fisuras, porque resulta un elemento débil y susceptible de fisurarse a su vez por retracción, despegándose del soporte. Un mortero epoxi, como se ha dicho, es mucho más confiable, ya que llega a formar cuerpo íntimo con el hormigón que se repara.

Como es sabido, cuando un elemento de hormigón pierde su esquema resistente original por causa de la fisuración, el resultado no suele ser su hundimiento. En general, lo que sucede es que el elemento adopta otro esquema resistente acorde con sus posibilidades. Como decía Ribera, las estructuras no trabajan como se las calcula, sino como se las dimensiona. 
Ejemplo frecuente de lo dicho es el forjado que, proyectado como semiempotrado, se articula en apoyos y pasa a trabajar como simplemente apoyado si la armadura negativa que realmente se colocó es insuficiente o está deficientemente anclada. Otros ejemplos se muestran en la figura 51, donde una viga fisurada (izquierda) provista de estribos inclinados llega a trabajar como colgada de sus armaduras; o una viga (derecha) que ha perdido su recubrimiento de tracción llega a trabajar como arco atirantado, si los anclajes de las barras son eficaces.

Por terminar con este mosaico de ejemplos ilustrativos de la muy variada patología del hormigón, incluiré algunas fotografías expresivas de un daño característico, esta vez no relacionado con fisuras. Me refiero al efecto del hielo.

Quizá sean los pavimentos de hormigón las estructuras que más experimentan estos perjudiciales efectos, y ello por varias razones. Por un lado, su gran superficie les hace especialmente vulnerables. Por otro, su paramento está permanentemente sometido al desgaste ocasionado por el tráfico. Por otro, en fin, las sales empleadas para el deshielo se diluyen en el agua que de él proviene y resulta así uno de los agentes más agresivos que puede imaginarse. La fotografía 52 es expresiva a este respecto.

Este problema es uno de los pocos que pueden considerarse resueltos gracias al empleo de un aireante. Son muchos los ensayos de laboratorio que han demostrado la eficacia de estos productos frente a ciclos de hielo y deshielo, mostrándose en la fotografía 53, a título de ejemplo, uno de estos ensayos recientemente realizado en el Instituto del Cemento de Viena. Se trata de dos muestras de un hormigón idéntico, de relación agua/cemento igual a 0,4 , sometidos a 45 ciclos de hielo. La única variante es que la muestra de la izquierda tiene incorporado un 4 por 100 de aire ocluido y puede apreciarse la diferencia de comportamiento.

Lo dicho es válido igualmente fuera del laboratorio. Yo tuve la feliz oportunidad de visitar un tramo de la autopista de hormigón Hannóver-Kassel en el que se había olvidado incorporar aireante al hormigón en una ocasión. El resultado puede verse en la fotografía 54 , realmente expresiva, que corresponde a la junta entre dos losas con y sin aireante.

Añadamos, por último, que un tratamiento eficaz de los hormigones sin aireante es el impregnar su superficie con una mezcla de aceite de linaza y gasolina al 50 por 100 . Dicho tratamiento (cuya efectividad muestra lo fotografía 55) suele dar buen resultado, aunque con él se pierde algo de adherencia en el pavimento. Normalmente debe repetirse cada año o cada dos años.

Fotor B. GUTIERREZ
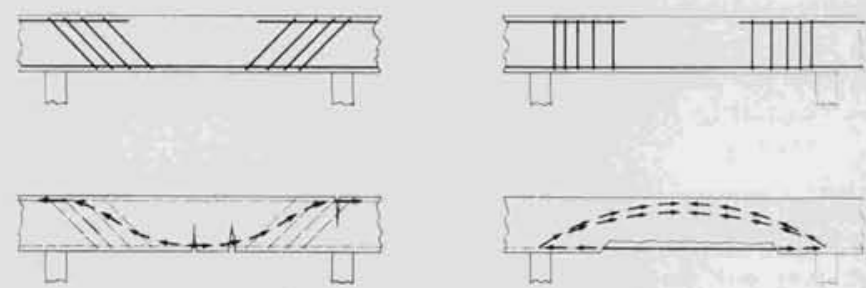

Fig. 51

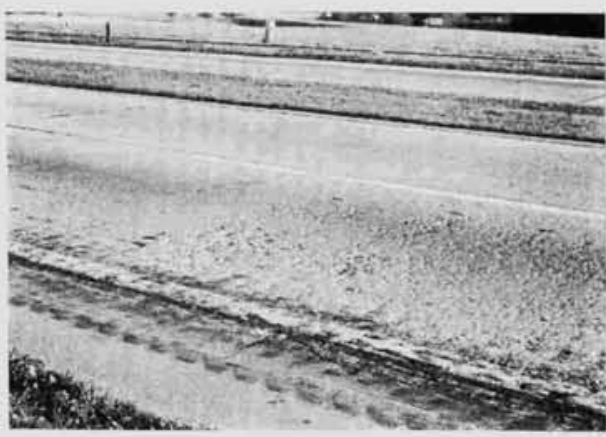

Fig. 52

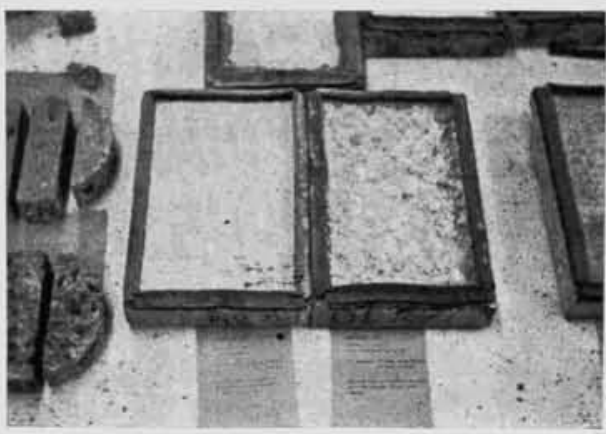

Fig. 53

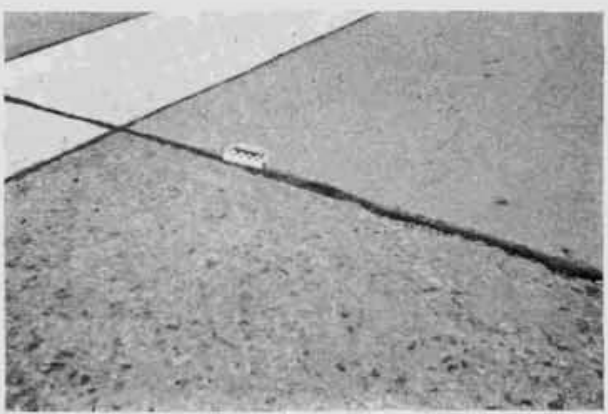

Fig. 54

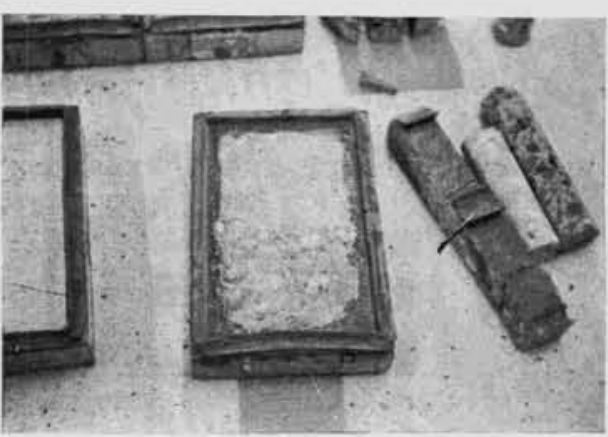

Fig. 55 


\section{ayudas de laboratorios}

Esta charla se ha alargado bastante y es hora de terminar. No hemos hablado del fenómeno de cicatrización, por el cual una fisura del hormigón puede colmatarse sola con un simple tratamiento de riegos abundantes, siempre que se den una serie de condiciones favorables desde el punto de vista físico y químico. Y cabría comentar otros detalles no menos interesantes. Pero me parece más útil dedicar los últimos minutos a considerar, desde un punto de vista práctico, el papel que pueden jugar en los problemas de patología los laboratorios especializados y qué clase de ayudàs podemos encontrar en ellos.

Cuando una obra de hormigón ya ejecutada muestra síntomas patológicos, expresivos de que algo raro está ocurriendo, una de las primeras comprobaciones que interesa realizar es la determinación de resistencias de ese hormigón. Para ello se recurre a una exploración esclerométrica de la estructura, en la que el "modus operandi» y la interpretación de resultados cobran una importancia excepcional.

Sería muy prolijo enumerar aquí con detalle todas las limitaciones y fuentes de error que tiene el esclerómetro, las cuales justifican el calificativo de «aparato peligroso» que suele dársele en los laboratorios, cuando cae en manos de personas no expertas. No debe olvidarse que el esclerómetro pretende dar una idea de la resistencia del material a través de la medición de su dureza superficial. Por tanto, el estado geométrico de la superficie, su grado de humedad, el soleamiento, etc., son variables que influyen en la lectura obtenida para un mismo hormigón, por no hablar del conocido efecto local de los áridos, sobre los que no debe golpearse directamente.

Hay otra idea que merece ser recordada. Todos los esclerómetros poseen una curva o tabla de equivalencia entre lecturas y resistencias. Esa curva no es más que un conjunto de valores medios que debe funcionar bien en todos los hormigones, lo cual significa que los errores pueden ser bastante grandes en un cierto hormigón y bastante pequeños en otro. Lo que sí es indudable es el valor comparativo que proporciona el esclerómetro de unas zonas a otras de una misma estructura, pudiendo asegurarse que a conjuntos de lecturas de valor doble corresponden resistencias aproximadamente dobles. Pero es mucho más aleatorio el asignar valores absolutos a las medidas, o, dicho de otro modo, el problema consiste en saber dónde está el cero de la escala o, si se prefiere, cuál es el coeficiente de paso que debe aplicarse para pasar de medidas relativas a absolutas.

La solución' a ese problema reside en la extracción y rotura de algunas probetas testigo de la estructura en cuestión, lo que proporciona unas resistencias reales que permiten "tarar» el esclerómetro para ese caso particular. De esta forma, todos los índices esclerométricos obtenidos cobran un valor absoluto.

Además de la exploración de resistencia de hormigones, los laboratorios suelen poseer aparatos para detectar el trazado de las armaduras. Rara vez la precisión de estos aparatos permite determinar el diámetro de las barras, especialmente si su recubrimiento es grande. A pesar de ello, estos detectores, de tipo magnético u otro, son útiles en casi todos los problemas que se presentan.

EI análisis químico de una muestra de hormigón endurecido permite determinar, entre otras cosas, el contenido en cemento por metro cúbico que se utilizó en su confección. Para que esta determinación sea precisa es necesario poseer muestras de los distintos componentes, incluido, por supuesto, el cemento, así como una cantidad mínima de $5 \mathrm{~kg}$ de hormigón, a ser posible en un solo bloque $o$ en pocos trozos grandes.

Otra actuación posible sobre una estructura con problemas es la medición de sus deformaciones y, especialmente, de la evolución de éstas, sean de tipo general (flechas) o localizado (abertura de fisuras). Una vigilancia atenta de estas evoluciones es fundamental para conocer lo que está sucediendo y/o la gravedad de lo que ha sucedido.

En fin, queda el recurso más o menos heroico de la prueba de carga. El objetivo de una prueba de carga es, generalmente, el de saber si la estructura se comporta bien y dentro del régimen elástico bajo la carga de servicio. En este caso, la prueba es no destructiva y en ella no deben sobrepasarse las cargas supuestas en el cálculo como máximas de utilización, ya que de otro modo se corre el riesgo de introducir lesiones permanentes en la estructura (fisuras o deformaciones no recuperables). Otras veces se pretende conocer el verdadero margen de seguridad de una estructura, en cuyo caso es obligado llevar hasta rotura algún elemento representativo de la misma. Naturalmente, este ensayo no tiene sentido más que cuando se repiten elementos idénticos o puede aislarse un trozo de un conjunto homogéneo, como puede ser el caso de un forjado. Pero lo que no debe hacerse es emplear valores de carga intermedios entre el que se presume ser el de servicio y el de rotura.

Por lo dicho se comprende que, en general, no es posible resolver con una prueba de carga el caso, que se presenta con cierta frecuencia en edificación, en que se desea saber si una estructura antigua de la que no se poseen planos, pero que consta fue dimensionada con holgura, es capaz de admitir una carga de utilización superior a la original de proyecto. 
La interpretación de una prueba de carga de servicio no es siempre fácil. Si el resultado no es claramente positivo, suelen presentarse situaciones enojosas a la hora de interpretar y decidir. En cualquier caso, la decisión no corresponde, en general, al laboratorio que realizó la prueba, el cual se limita a trasladar los resultados al técnico de la obra, y a él toca la responsabilidad de decidir a su criterio. Gajes de la profesión.

Como orientación, y hablando en términos muy generales, una merma de resistencia de hasta un 15 por 100 puede admitirse siempre. Una merma mayor del 30 por 100 es temerario aceptarla. $Y$ entre ambos valores se coloca la zona de incertidumbre.

\section{a modo de moraleja}

Si hubiera que sacar una moraleja de todo lo expuesto, yo escogería una muy sencilla en forma de consejo, que es tan fácil de cumplir como fácil de olvidar. No me refiero al tan repetido consejo de que hay que analizar todos los materiales antes de hacer una obra, para evitar disgustos después. No, no me atrevo a pedir tanto. La experiencia demuestra que eso es un ideal que rarísimas veces se alcanza, por aquello de las prisas de obra, la improvisación a la española, etc.

Me refiero a otra cosa, más fácil. Me refiero a la conveniencia de guardar muestras de todo, cementos, áridos, aguas, etc., bien envasados, con su etiqueta bien clara y mientras dure la obra. En cuanto se acaba, se pueden tirar. Pero mientras se construye hay que guardarlas..., por si vienen mal dadas.

Las posibilidades que hay de dictaminar y resolver correctamente los problemas de una obra que presenta problemas, son cien veces mayores si se dispone de muestras de todo. Las muestras permiten analizar por separado las diversas causas posibles, y cuando no hay muestras, la complejidad y el amontonamiento son tan grandes que alcanzar un éxito es casi milagroso.

Si como fruto de esta larga charla obtengo el que uno sólo de mis asistentes constructores se dedique en lo sucesivo a conservar muestras (¿nueva partida de cemento?, ¡muestra y etiqueta!), os aseguro que mi satisfacción rebasará con creces a la mucha paciencia que habéis derrochado escuchándome. Y nada más. Muchas gracias.

\section{bibliografía recomendada}

\section{libros}

La pathologie du béton armé, por Henry Lossier. Editorial Dunod, París, 1952.

Lessons from failures of concrete structures, por Jacob Feld. Monografía núm. 1 del American Concrete Institute, 1964.

Fisuras y grietas en morteros y hormigones, por A. Joisel. Editores Técnicos Asociados, Barcelona, 1965.

Dissesti statici delle strutture edilizie. Diagnosi e consolidamento, por Sisto Mastrodicasa. Editado por U1rico Hoepli, Milán, 1965.

Dégradation, entretien et réparation des ouvrages du génie civil, por Sidney M. Johnson. Editorial Eyrolles, París, 1969.

\section{articulos}

Notes sur la technique actuelle du béton armé. Chapitre VII: Causes des desordres, por André Paduart. Annales des Travaux Publics de Belgique, junio 1953.

Morfología de las fisuras en construcciones de hormigón en masa y armado, por B. Bukowski. Simposio RILEM de Estocolmo, 1957.

Cracks in existing reinforced concrete buildings, por Kazuo Ohno. Simposio RILEM de Estocolmo, 1957.

Failures of concrete structures, por Jacob Feld. Journal of the American Concrete Institute, núm. 6, vol. 29 (ACI proceedings, vol. 54), diciembre 1957.

Effect of design and details on concrete deterioration, por P. D Miesenhelder. Journal of the American Concrete Institute, núm. 7, vol. 31, enero 1960.

Conventional methods of repairing concrete, por Lewis $\mathrm{H}$. Tuthill, Journal of the American Concrete Institute, núm. 2, vol. 32 (ACI proceedings, vol. 57) agosto 1960.

La corrosione delle strutture metalliche nelle opere in calcestruzzo, por Mario M. Jacopetti. L'Ingegnere, junio 1963.

Considerazioni sulla patología del calcestruzzo armato, por Cestelli Guidi, Morandi y otros. L'Industria Italiana del Cemento, julio 1963.

La fisuración en vigas de hormigón armado, por A. García Meseguer. INFORMES DE LA CONSTRUCCION, núm 209, abril 1969. 


\section{Pathologie des ouvrages de mafonmerie}

A. García Meseguer, -Dr. ingénieur des Ponts et Chaussées

Après une brève allusion aux ouvrages métalliques et en bois, l'auteur analyse en détail la pathologie du béton en tant que matériau structural et fait une étude des diverses fissures qui peuvent se présenter, ainsi que leur signification. Il fait ensuite une classification des causes les plus fréquentes d'anomalies en structures dé béton et donne des exemples illustrés et complétés par un bref exposé de l'assistance que les laboratoires spécialisés peuvent prêter aux techniciens ayant à faire face à des problèmes de pathologie dans leurs ouvrages.

\section{Patholiogy of Masomm Work}

A. García Meseguer, Dr. civil engineer

After a brief reference to metal and timber structures, this paper analyses in detail the pathology of concrete as a structural medium, and a study is made of the various types of cracks which may arise, and their significance. A systematic classification is given of the most frequent anomalies that are found in concrete structures, and illustrative examples are cited. Finally a brief account is given of the kind of help that technicians can obtain from specialised laboratories, when encountering pathological problems in their works.

\section{Pathologie der Muruerwerke}

Dr. A. García Meseguer, Bauingenieur

Nach einem kurzen Hinweis auf Metall- und Holzkonstruktionen wird eingehend die Pathologie des Betons als Strukturmaterial analysiert; es werden die verschiedenen Risse, die hier auftraten können, sowie ihre jeweilige Bedeutung untersucht. Anschliessend werden die häufigsten Schadensursachen in Betonstrukturen systematisiert und klassifiziert unter Darstellung erläuternder Beispiele. Zum Schluss werden kurz die Hilfestellungen geschrieben, welche spezialisierte Labors jenen Technikern geben können, die sich bei ihren Bauwerken mit Problemen der Pathologie konfrontiert sehen. 